\title{
Nickel Oxide (NiO) Devices and Applications: A Review
}

\author{
Sani Garba Danjumma \\ Department of Sciences, \\ Kebbi State Polytechnic, Dakingari, Nigeria.
}

\author{
Yakubu Abubakar \\ Department of Physics, \\ Kebbi State University of Science and Technology, Aliero, \\ Nigeria.
}

\author{
Sahabi Suleiman \\ Department of Sciences, \\ Kebbi State Polytechnic, Dakingari, Nigeria.
}

\begin{abstract}
The prospects for using nanomaterials with diameters of $<100 \mathrm{~nm}$ in number of applications is being widely researched today across multiple domains such as biology, physics, chemistry, cosmetics, optical components, pharmaceutical drug manufacture, polymer science, mechanical engineering, and toxicology. In recent years, nanostructured materials have received steadily growing attention as a result of their peculiar and fascinating properties and applications. The electrical, optical, magnetic, thermal and mechanical properties of materials is often important when materials selection and processing decisions are being made during the design of a device. The applications of Nickel oxide (NiO) today is found in semiconductors, capacitor-inductor devices, tuned circuits, transparent heat mirrors, thermistors and varistors, batteries, micro-supercapacitors, electrochromic and chemical or temperature sensing devices. It is used in preparation of nickel cermet, plastics and textiles, in nanowires, nanofibers and specific alloy and catalyst applications. It is also used as an antiferromagnetic layers, accelerators and radar absorbing materials, aerospace and active optical filters. In this paper, current and future device applications of $\mathrm{NiO}$ is reviewed.
\end{abstract}

\section{Key Words-Nickel Oxide, Device, Applications}

\section{INTRODUCTION}

The prospects for using nanomaterials in number of applications is being widely researched today across multiple domains such as biology, physics, chemistry, cosmetics, optical components, pharmaceutical drug manufacture, polymer science, mechanical engineering, and toxicology. In recent years, nanostructured materials have received steadily growing attention as a result of their peculiar and fascinating properties and applications. Among the various nanomaterials, metal oxides (with $\mathrm{NiO}$ inclusive) have attracted increasing technological and industrial interest. This interest has mainly to do with their properties (optical, magnetic, electrical, and catalytic properties) associated with general characteristics such as mechanical hardness, thermal stability or chemical passivity (Mohammad and Leila, 2014). Nickel oxide is a prominent example among metal oxides and can be manufactured by thermal decomposition of freshly prepared nickel hydroxife by sol gel route at $300^{\circ} \mathrm{C}\left(572^{\circ} \mathrm{F}\right)$. It has a melting point of $1955^{\circ} \mathrm{C}$ and a density of $6.67 \mathrm{~g} / \mathrm{cm}^{3}$ (AzoNano, 2013).

Nickel oxide $(\mathrm{NiO})$ is an attractive semiconductor, because its properties are very useful for various photocatalytic, battery, electrochromic and chemical sensing applications (Thomas et al., 2014). Nio is also an attractive material for applications in preparation of nickel cermet for the anode layer of solid oxide fuel cells, in lithium nickel oxide cathodes for lithium ion microbatteries, in electrochromic coatings, plastics and textiles, in nanowires, nanofibers and specific alloy and catalyst applications. It is also used as a catalyst and as antiferromagnetic layers, in light weight structural components in aerospace, in active optical filters, in cathode materials for alkaline batteries and materials for gas or temperature sensors, such as $\mathrm{CO}$ sensor, $\mathrm{H}$ sensor, and formaldehyde sensors (AzoNano, 2013).

Al-Kuhaili et al. (2015), deposited Nickel oxide thin films by thermal evaporation and observed the desired properties that are necessary for their utilization in the energy-saving transparent heat mirror multilayer structures. This was manifested by their smooth and dense surfaces that had a sub-nano-meter surface roughness, and oriented crystalline growth. According to Baptiste et al. (2016), $\mathrm{NiO}$ is used for making electrical ceramics such as thermistors and varistors e.g. ferrites (nickel zinc ferrite), Pigments for ceramic, glasses and glazes. Gold doped nickel oxide films can be used as transparent electrodes in optoelectronic devices.

\section{MICRO-SUPERCAPACITOR}

Micro scale supercapacitors enable novel applications in wireless microsensors and microelectronics devices (Richard and Travis, 2011). Jing Et al. (2018), proposed a rational design of thin film, flexible micro-supercapacitors with in-plane inter-digital electrodes, where the electrodes were fabricated using the oblique angle deposition technique to grow oblique $\mathrm{Ni} / \mathrm{NiO}$ nanowire arrays directly on polyimide film. The obtained electrodes are observed to have a high specific surface area and good adhesion to the substrate compared with other in-plane microsupercapacitors. Meanwhile, the as-fabricated micro- 
supercapacitors have good flexibility and satisfactory energy-storage performance, exhibiting a high specific capacity of $37.1 \mathrm{~F} / \mathrm{cm}^{3}$, a high energy density of 5.14 $\mathrm{mWh} / \mathrm{cm}^{3}$, a power density of up to $0.5 \mathrm{~W} / \mathrm{cm}^{3}$, and good stability during charge-discharge cycles and repeated bending-recovery cycles, respectively as shown in Fig. 2.1 They therefore concluded that, the obtained microsupercapacitors can be used as ingenious energy storage devices for future portable and wearable electronic applications.
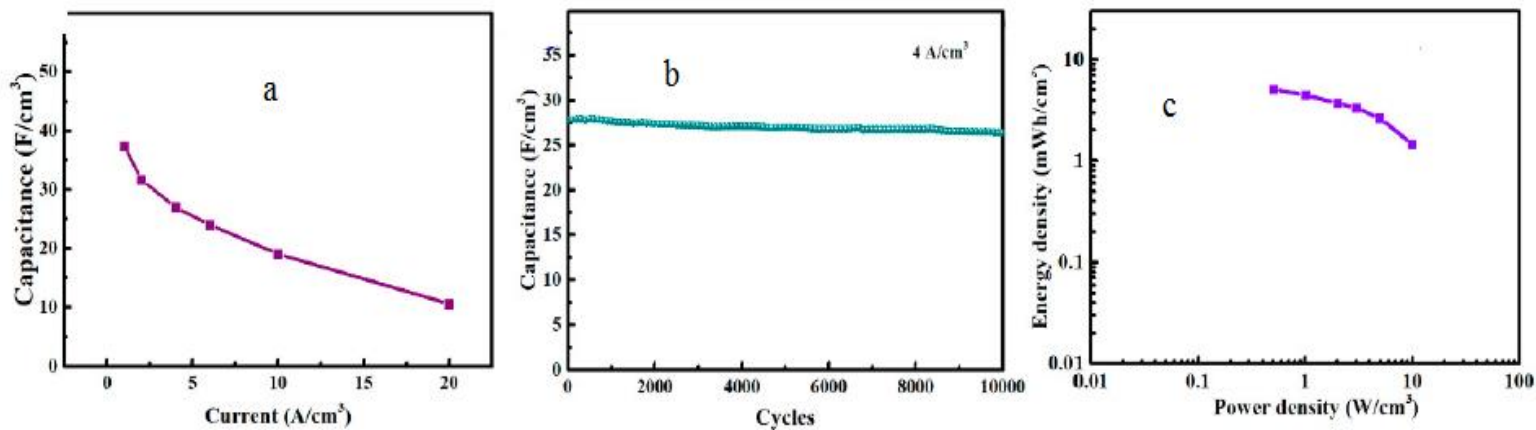

Fig. 2.1: (a) comparison of capacitances of the micro-supercapacitors devices at varied galvanostatic charge-discharge current densities; (b) capacitance retention on cycle number at a current of $4 \mathrm{~A} / \mathrm{cm}^{3}$; (c) energy and powder densities of the micro-supercapacitors devices (Jing Et al., 2018)

\section{DIELECTRIC-BASED DEVICES}

A material is classified as "dielectric" if it has the ability to store energy when an external electric field is applied. The dielectric material increases the storage capacity of the capacitor by neutralizing charges at the electrodes, which ordinarily would contribute to the external field (Richard and Travis, 2011). Ahmad et al. (2017), in their study highlighted the development of microwave-absorbing material from NZF by adding natural fibres, Oil Palm Empty Fruit Bunch (OPEFB) and polycaprolactone (PCL). They prepared Nickel-zinc ferrite material using the conventional solid-state reaction technique. A Thermal Hake blending machine was used in blending the powder structure of NZF + OPEFB + PCL, which made it homogeneous. The composite was characterised and the effective permittivity and effective permeability was obtained over a broad frequency range from 8 to $12 \mathrm{GHz}$ at room temperature. It was observed that the values of effective permittivity and permeability increased as the content of NZF increased.

Raju and Murphy (2012), reported that, for a composite; nickel-zinc ferrite + paraformaldehyde, increase in the volume of paraformaldehyde decreases the permittivity, permeability, and dielectric and magnetic loss. Such magnetic composites are candidates for capacitor-inductor integrating devices such as electromagnetic interference filters in RF communications. .

Ravi et al. (2012), prepared $\mathrm{Ni}-\mathrm{Cu}$ ferrites of different compositions by a conventional double sintering ceramic technique. They investigated the electrical conductivity of $\mathrm{Ni}-\mathrm{Cu}$ ferrites of various compositions from room temperature to well beyond the Curie temperature. Composition and frequency dependent dielectric properties of mixed $\mathrm{Ni}-\mathrm{Cu}$ ferrites have been measured at room temperature in the frequency range 1 to $13 \mathrm{MHz}$ using a $\mathrm{HP}$ 4192A impedance analyser. They reported that, among all the ferrites, the composition $\mathrm{Ni}_{0.8} \mathrm{Cu}_{0.2} \mathrm{Fe}_{2} \mathrm{O}_{4}$ exhibits the highest value of dielectric constant, dielectric loss tangent and complex dielectric constant.
Gaurav et al. (2015), studied the improvement in dielectric and optical properties of nematic liquid crystal (NLC) by doping of nickel oxide (NiO) nanoparticles. They observed the dielectric and optical properties of pure and doped cells in order to understand the influence of $\mathrm{NiO}$ nanoparticles in the pure NLC. Detailed studies of dielectric parameters such as dielectric permittivity, dielectric loss and dielectric loss factor as a function of frequency with temperature were carried out. It has been observed that on doping the nanoparticles in NLC, the value of dielectric parameters (dielectric permittivity, dielectric loss and dielectric loss factor) decreases.

Hayati (2018), reports on the electrical and nanostructural properties of polymer-based materials in corporation with $\mathrm{NiO}$ (Nickel oxide) in weight concentrations of $0.2 \%, 0.4 \%$, and $0.8 \%$ of PVA (polyvinyl alcohol) polymer. The permittivity value of $\mathrm{NiO} / \mathrm{PVA}$ dielectric is found to be higher than for other presented samples, and therefore, it can be introduced as a good gate dielectric material.

Banerjee et al., (2012), synthesized Barium strontium titanate (BST) ceramics $\left(\mathrm{Ba}_{0.6} \mathrm{Sr}_{0.4}\right) \mathrm{TiO}_{3}$ by solid state sintering using barium carbonate, strontium carbonate and rutile as the precursor materials. The samples were doped with nickel oxide in different proportions and their dielectric properties are studied. It was observed that the dielectric properties of BST were modified significantly with nickel oxide doping. These ceramics held promise for applications in tuned circuits.

The composite of oil palm empty fruit bunch fiber (OPEFB) which is the waste product of oil palm industry, environmentally friendly polycaprolactone (PCL) and nickel oxide (NiO). The three were fabricated by compounding all materials in the Thermo Hake blending machine by Ahmad et al. (2015). The dielectric properties of the substrates were measured using open ended coaxial method for microwave frequency range between $0.2 \mathrm{MHz}$ and $20 \mathrm{GHz}$. The results reveal that the permittivity values of the composite can be tuned by changing the ratio of $\mathrm{OPEFB} / \mathrm{PCL} / \mathrm{NiO}$ prior to 
compounding and blending. These composites may offer alternatives to Teflon, which is made primarily from petroleum, for applications in radio and communications, especially in the fabrication of antennas, transmission and other microwave components.

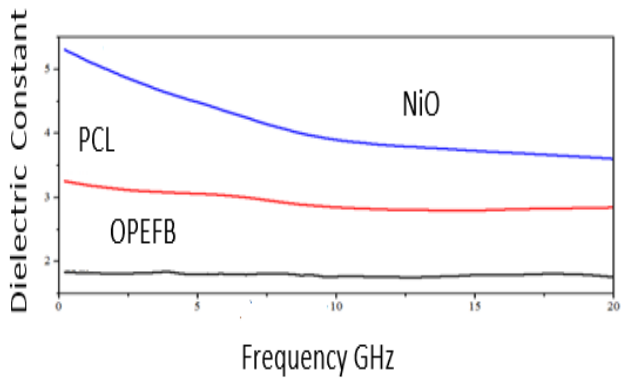

Fig. 3.1: Dielectric constant for pure OPEFB, PCL and $\mathrm{NiO}$

Fig. 3.1 and 3.2 show the variation in dielectric properties of pure OPEFB, PCL and $\mathrm{NiO}$. It can be observed that $\mathrm{NiO}$ exhibit the highest dielectric constant and loss factor while OPEFB exhibit the lowest dielectric constant and loss factor (Ahmad et al., 2015).

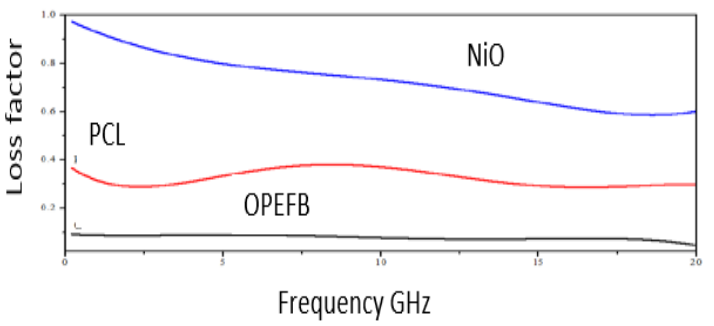

Fig. 3.2: Loss factor for pure OPEFB, PCL and NiO

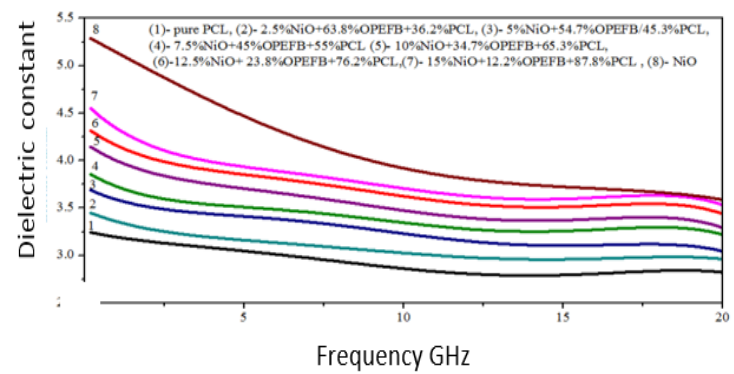

Fig. 3.3: Dielectric constant for OPEFB/PCL/NiO substrate (Ahmad et al., 2015).

In Fig. 3.3, it can be clearly observed that the dielectric constant of all composites decreases as frequency increases. Likewise in figure 3.4, it can be observed that the loss factor decreases with increasing frequency (Ahmad et al., 2015).

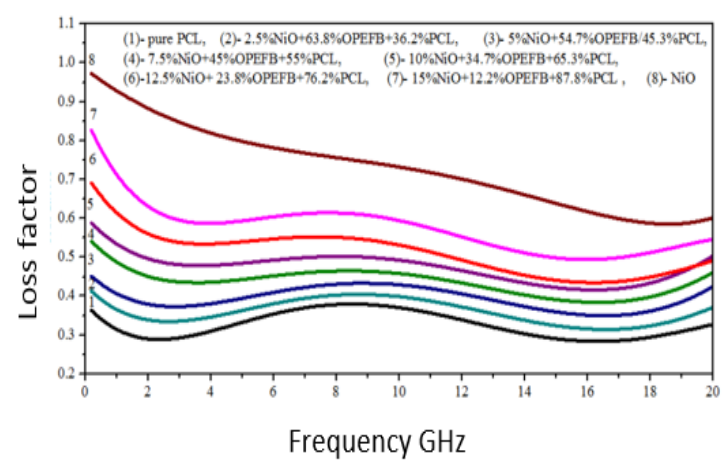

Fig. 3.4: Loss factor for OPEFB/PCL/NiO substrate (Ahmad et al., 2015).

\section{ELECTROCHROMIC DEVICES (ECDS)}

Electrochromism refers to the persistent and reversible change of optical properties of a material by an applied voltage pulse. Electrochromic (EC) devices have been extensively studied because of their commercial applications in smart windows of green buildings, display devices and thermal control of equipment. Electrochromic (EC) devices are able to control the throughput of visible light and solar radiation into buildings and control energy efficiency by modulating optical transmittance (Busra, 2017). EC devices are also applied in smart windows of green buildings, fullangle information displays, controlled reflectance mirrors and thermal control of satellites. Electrochromism refers to the phenomenon that the optical properties can be switched reversibly and persistently in materials induced upon a small external voltage (Zhou et al., 2017).

A considerable amount of studies has been recently reported on $\mathrm{NiO}$ as a counter electrode for $\mathrm{NiO} / \mathrm{WO}_{3}$ electrochromic applications (Patel, et al., 2016). Pilban-Jahromi, et al. (2012), reported that $\mathrm{NiO}$ is an anodically coloring inorganic material, in oxidized state, the color of $\mathrm{NiO}$ turns to dark bronze and colourless in the reduced state.

The most commonly used anodic oxide-based Electrochromic (EC) materials are $\mathrm{Ni}$ and Ir oxide. These oxides can both change from a transparent state to a neutral colored one upon extraction of protons or insertion of $\mathrm{OH}-$ ions. Ir is limited to use due to its high cost and limited supply. Hence, Ni oxide has been studied extensively because of its high optical modulation, fast switching speed, good cyclic stability, memory effect and low cost. Furthermore, $\mathrm{NiO}$ can also be ion storage films in the standard EC device, which have the color overlay or complementary effect. It is widely accepted that the EC performance of $\mathrm{NiO}$ is attributed to the injection/extraction of electrons and cations, which strongly depend on the diffusion length of ions and the appropriate surface area (Zhou et al., 2017).

Michelle et al. (2016), fabricated two electrochromic NiO materials through a similar electro-deposition technique, apart from different lower depositing potentials, on a conductive ITO substrate. They realised that, the electrochromic capabilities of the two $\mathrm{NiO}$ materials are encouraging. The coloration efficiency for deposition 
process 1 and deposition process 2 are 49 and $17 \mathrm{~cm}^{2} \mathrm{C}^{-1}$, respectively while the switching time for deposition 1 for coloration and bleaching is 5.7/7.4 seconds.

$\mathrm{NiO}$ played a vital role in EC but there are still difficulties in commercial applications of $\mathrm{NiO}$ as promising EC materials due to its slow switching speed, low color contrast and poor cycling durability. Hence, it is important to design a material with nanostructure to obtain fast insertion kinetics and enhanced durability.

\section{MICRO-BATTERIES AND NANO-ELECTRONIC DEVICES}

Lalithambika et al. (2016) constructed $\mathrm{NiO}$ nano wire devices with gold and platinum electrodes and studied the effect of the electrodes in the transport properties. Apart from the pristine $\mathrm{NiO}$ nano device, $\mathrm{Fe}$ and $\mathrm{N}$ atoms are substituted in the device and their effects are also studied. From the obtained results, gold electrode devices are having better performance than the platinum electrode devices. The transmission and PDOS spectra of the gold electrode $\mathrm{NiO}$ nano devices shows that $\mathrm{N}$ doped $\mathrm{NiO}$ nano device is performed well than the other two $\mathrm{NiO}$ nano devices with gold electrodes. In the case of platinum electrode $\mathrm{NiO}$ nano devices, the $\mathrm{Fe}$ doped $\mathrm{NiO}$ nano device shows better performance than the other two devices.

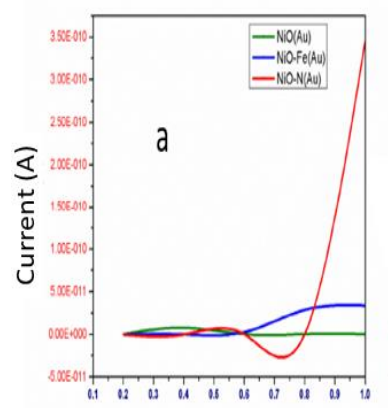

Voltage (V)

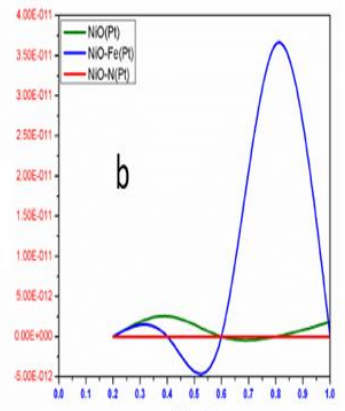

Voltage (V)
Fig. 5.1: V-I characteristics of (a) $\mathrm{NiO}$ nano device with golden electrodes and (b) $\mathrm{NiO}$ nano device with platinum electrodes (Lalithambika et al., 2016).

The V-I characteristics of the $\mathrm{NiO}$ nano devices with gold atoms in Fig. 5.1(a) give the current in the order of $10^{-10}$ amperes whereas the platinum $\mathrm{NiO}$ nano devices show the current in the order of $10^{-12}$ amperes in Fig. 5.1(b) (Lalithambika et al., 2016). The composites can therefore serve as good electrodes and hence useful in manufacturing micro-batteries.

Jason et al. (2007), synthesized high-definition metaloxide-metal (MOM) heterojunction nanowires in the $\mathrm{Au}-$ $\mathrm{NiO}-\mathrm{Au}$ system using a template-based method. These nanowires are $70 \mathrm{~nm}$ in diameter and $7 \mu \mathrm{m}$ in total length, with a 100 to $300 \mathrm{~nm}$ wide $\mathrm{NiO}$ segment sandwiched between the $\mathrm{Au}$ nanowires axially. These $\mathrm{Au}-\mathrm{NiO}-\mathrm{Au}$ nanowires have been incorporated into high-quality singlenanowire devices, fabricated using a direct-write method. The current-voltage (I-V) responses of individual $\mathrm{Au}-\mathrm{NiO}-$ $\mathrm{Au}$ nanowires have been measured as a function of temperature in the range 298 to $573 \mathrm{~K}$. From figure 5.2, the I- $\mathrm{V}$ response at room temperature has been found to be nonlinear, it becomes more linear and less resistive with increasing temperature. These types of MOM nanowires are likely to offer certain advantages over all-oxide nanowires in fundamental size-effect studies, and they could be potentially useful as nanoscale building blocks for multifunctional nanoelectronics of the future.

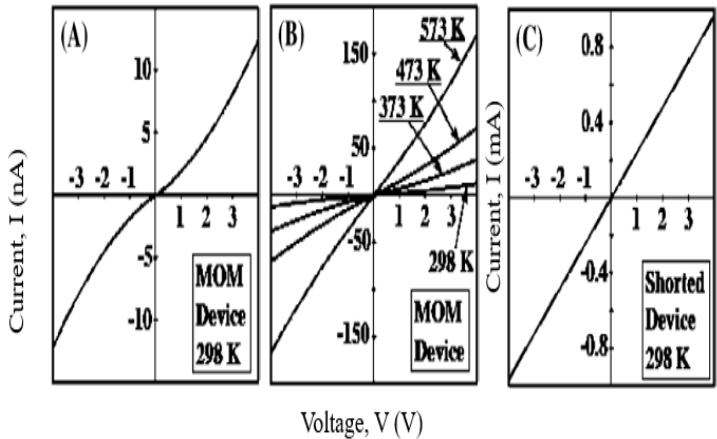

Fig. 5.2: I-V responses from the device pictured in Fig. 5 at: (A) $298 \mathrm{~K}$ and (B) at $298 \mathrm{~K}, 373 \mathrm{~K}, 473 \mathrm{~K}$, and $573 \mathrm{~K}$. (C) I-V response from the shorted device at $298 \mathrm{~K}$. Note the vastly different ordinate (I) scales in the top [(A) and (B)] and the bottom (C) plots (Jason et al., 2007).

\section{GAS SENSORS}

Irudaya et al. (2016), prepared pure and $\mathrm{Li}$ doped $\mathrm{NiO}$ nanoparticles by a cost-effective sol-gel method. All the samples exhibit cubic structure. Photoluminescent emission spectra reveal the blue shift exhibited by the synthesized nanoparticles. Hence these $\mathrm{Li}$ doped $\mathrm{NiO}$ nanoparticles can be used for catalytic and gas sensor applications.

Nanocomposite $\mathrm{NiO}: \mathrm{Au}$ thin films, formed by gold nanoparticles embedded in a nickel oxide matrix, have been grown by reactive pulsed laser deposition (R-PLD). The $\mathrm{NiO}: \mathrm{Au}$ nanocomposites have been tested as hydrogen sensors. Embedding $\mathrm{Au}$ nanoparticles into the $\mathrm{NiO}$ film matrix reduced the sensors operating temperature and improved their performance by orders of magnitude as shown in figure 6.2 (Fasaki et al., 2018).

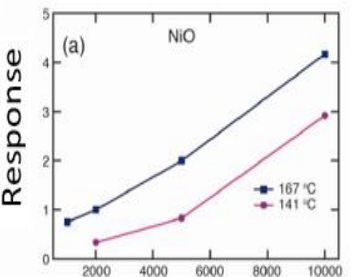

Hydrogen concentration (ppm)

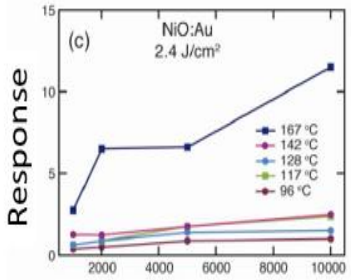

Hydrogen concentration (ppm)

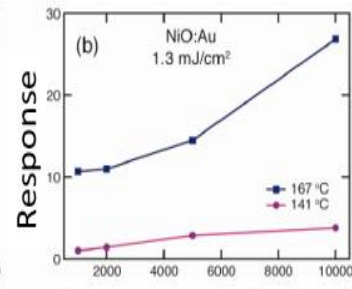

Hydrogen concentration (ppm)

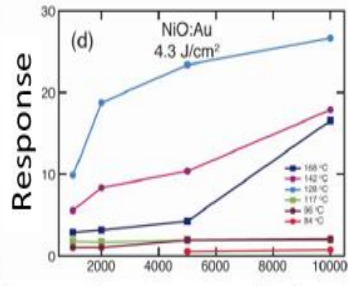

Hydrogen concentration (ppm)
Fig. 6.2: Summary of sensing results for all temperatures and hydrogen concentrations in air, obtained (a) with the reference $\mathrm{NiO}$ sample, (b) with $\mathrm{NiO}: \mathrm{Au}$ nanocomposite with $15.6 \mathrm{wt} \%$ Au concentration $\left(1.3 \mathrm{~J} / \mathrm{cm}^{2}\right.$ laser fluence), (c) with $\mathrm{NiO}: \mathrm{Au}$ nanocomposite with $23.5 \mathrm{wt} \%$ Au concentration $\left(2.4 \mathrm{~J} / \mathrm{cm}^{2}\right.$ laser fluence), and (d) with $\mathrm{NiO}: \mathrm{Au}$ nanocomposite with $44.4 \mathrm{wt} \%$ Au concentration (4.3 J/ $\mathrm{cm}^{2}$ laser fluence) (Fasaki et al., 2018). 


\section{MICROWAVE ABSORBERS}

The use of materials for microwave absorption is a topics of interest to various scientific communities. Among those interested in special materials are accelerator builders, microwave tube experts, fusion device builders and materials scientists from various areas of technology.

In their effort to determine the microwave absorbing properties of $\mathrm{NiO}$ and $\mathrm{Co}_{0.2} \mathrm{Ni}_{0.4} \mathrm{Zn}_{0.4} \mathrm{Fe}_{2} \mathrm{O}_{4}$ Ferrite Composites, Pei-Jiang et al. (2018), prepared hierarchical spherical $\mathrm{NiO}$ particles by using a hydrothermal method, and synthesized CNZF ferrites by using a sol-gel auto-ignition method. Electromagnetic and microwave absorption properties of these samples were systematically studied. Due to the high impedance matching characteristic, large attenuation capability, and well-coupled layer, the doublelayer absorbers, with the CNZF composite as the absorption layer and $\mathrm{NiO}$ composite as the matching layer, showed promising reflection loss (RL) values, wider absorbing bandwidths, and smaller thicknesses, as compared with the individual single-layer absorbers. With the optimal total thickness of $3.2 \mathrm{~mm}$, the absorber exhibited a maximum RL value of $-67.0 \mathrm{~dB}$ at $9.2 \mathrm{GHz}$. It is believed that these new double-layer absorbers could be promising candidates as advanced microwave materials for various practical applications.
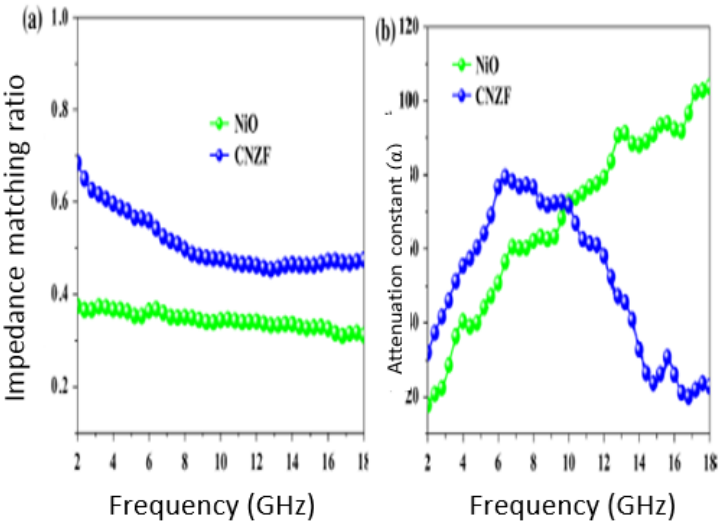

Fig. 7.1: (a) Impedance matching ratio, (b) attenuation constant ( $\alpha$ ) of the $\mathrm{NiO}$ and CNZF composites (Pei-Jiang et $a l, 2018)$.

Fig. 7.1(a) illustrates the impedance matching ratios of the $\mathrm{NiO}$ and CNZF composites. As observed, CNZF has a more suitable impedance matching ratio over the whole frequency region $(2-18 \mathrm{GHz})$, as compared with the $\mathrm{NiO}$ sample. In fact, the impedance matching ratios of both the $\mathrm{NiO}$ and CNZF samples are higher than 0.3. As shown in Fig. 7.1(b), the attenuation constant $(\alpha)$ indicates an integral loss effect including dielectric loss and magnetic loss, which is given in equation (1) (Pei-Jiang et al, 2018).

$$
\alpha=\frac{\sqrt{2 \pi f}}{C} \mathrm{X} \sqrt{\left(\mu^{\prime \prime} \varepsilon^{\prime \prime}-\mu^{\prime} \varepsilon^{\prime}\right)+\sqrt{\left(\mu^{\prime \prime} \varepsilon^{\prime \prime}-\mu^{\prime} \varepsilon^{\prime}\right)^{2}+\left(\mu^{\prime} \varepsilon^{\prime \prime}-\mu^{\prime \prime} \varepsilon^{\prime}\right)^{2}}}
$$

Ravindra et al., (2017) synthesized $\mathrm{Ni}_{0} .2 \mathrm{Co}_{0.3} \mathrm{Zn}_{0.5} \mathrm{Fe}_{2} \mathrm{O}_{4}$ ferrite nanoparticle and PANI/ $\mathrm{Ni}_{0} .2 \mathrm{Co}_{0.3} \mathrm{Zn}_{0.5} \mathrm{Fe}_{2} \mathrm{O}_{4}$ ferrite nanocomposite by sol-gel auto combustion method and in situ polymerization method. They studied the electromagnetic properties of the composite and reported that, the composite exhibits excellent absorption performance over a broad band range in the radar band with good electromagnetic properties. PANI/ $\mathrm{Ni}_{0 .} 2 \mathrm{Co}_{0.3} \mathrm{Zn}_{0.5} \mathrm{Fe}_{2} \mathrm{O}_{4} \quad$ nanocomposite improves electromagnetic properties compared with PANI or ferrite.

Shown in Fig. 7.2(A) and 7.2(B), the minimum value of reflection loss was $-14.40 \mathrm{~dB}$ at the $18 \mathrm{GHz}$ frequency for $\mathrm{Ni}_{0.2} \mathrm{Co}_{0.3} \mathrm{Zn}_{0.5} \mathrm{Fe}_{2} \mathrm{O}_{4}$ nanoparticles of thickness $3.0 \mathrm{~mm}$ and $22.58 \mathrm{~dB}$ at $18 \mathrm{GHz}$ frequency for PANI/Ni $\mathrm{Ni}_{0.2} \mathrm{Co}_{0.3} \mathrm{Zn}_{0.5} \mathrm{Fe}_{2} \mathrm{O}_{4}$ nanocomposite of thickness $3.0 \mathrm{~mm}$. So microwave absorption is increased with PANI (Ravindra et al., (2017).
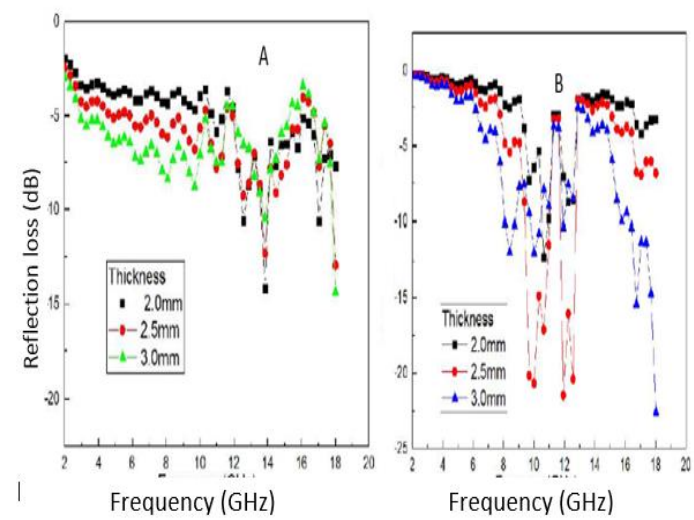

Fig. 7.2: Absorption characteristics of (A) $\mathrm{Ni}_{0 .} 2 \mathrm{Co}_{0.3} \mathrm{Zn}_{0.5} \mathrm{Fe}_{2} \mathrm{O}_{4}$ ferrite nanoparticles and (B) PANI/ $\mathrm{Ni}_{0} 2 \mathrm{Co}_{0.3} \mathrm{Zn}_{0.5} \mathrm{Fe}_{2} \mathrm{O}_{4}$ ferrite nanocomposite

\section{SOLAR CELLS}

There is need for affordable, clean, efficient, and sustainable solar cells. Photovoltaic (PV) cells employ the semiconducting materials to covert the light into electricity when exposed to light (Jeon, et al., 2015). Kingsley et al. (2018), fabricated Metal oxide $\mathrm{TiO}_{2} / \mathrm{NiO}$ heterojunction solar cells using the spray pyrolysis technique. The optoelectronic properties of the heterojunction were determined. The fabricated solar cells exhibit a short-circuit current of $16.8 \mathrm{~mA}$, open-circuit voltage of $350 \mathrm{mV}$, fill factor of 0.39 , and conversion efficiency of $2.30 \%$ under 
$100 \mathrm{~mW} / \mathrm{cm}^{2}$ illumination. Therefore, their study will help advance the course for the development of low-cost, environmentally friendly, and sustainable solar cell materials from metal oxides. Fig. 8.1 depicts generation of electricity by a solar cell using a P-N junction.

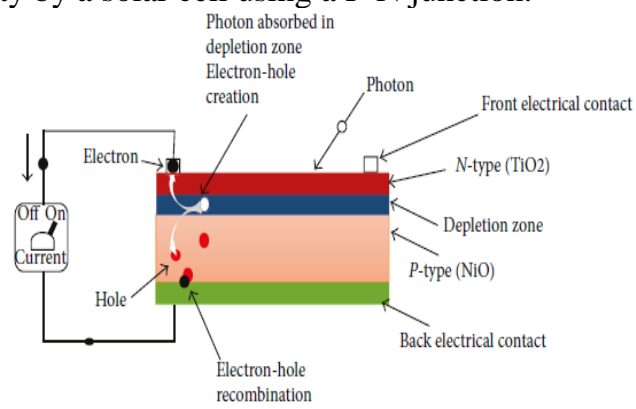

Fig. 8.1: Solar cell generation of electricity using a P-N junction (Kingsley et al., 2018)

\section{THIN FILM TRANSISTORS (TFTS)}

Thin film transistors (TFTs) take place commercially in today's technology, such as flat panel displays, smart phones and computers (Kasap and Rowlands, 2000). These devices facilitate the advancing of video system technology by enabling the large dimension displays (Liao et al., 2005). They are most commonly utilized as the pixel switching components in flat panel displays (Kuo and Nominanda, 2006). Additionally, this technology finds several applications apart from the display technologies, such as XRay detection, microelectronic devices (memories), chemical sensors and bio-chemical sensors (Estrela and Migliorato, 2007).

TFTs are kind of field effect transistors principally containing three terminals (source, gate and drain) and including semiconducting, conducting and dielectric layers. The semiconducting material is located between source and drain terminals; whereas, the dielectric one is placed between the semiconducting material and the gate (Li et al., 2016).

$\mathrm{NiO}$ is a promising material to fabricate low cost p-type oxide TFTs. Solution-based processing techniques are rather attractive than vacuum-based processes due to their simplicity, low cost and high quality films. Solutionprocessed $\mathrm{NiO}$ based p-type TFTs have been reported many times (Liu et al., 2016). The schematic representation of cross sectional solution-processed $\mathrm{NiO}$ based p-type TFT structure is provided in Fig. 9.1.

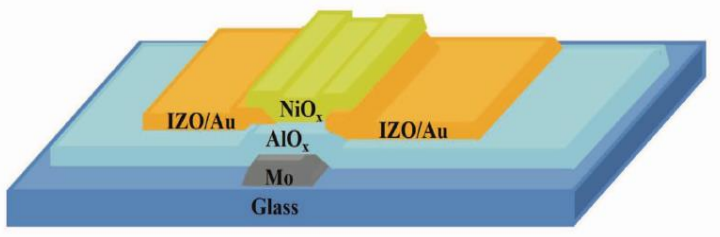

Fig. 9.1: Schematic cross-section of solution-processed NiO based TFT with a bottom-gate bottom-contact structure. NiOx based active layers and the AlOx gate insulator are deposited by spin coating (Li et al., 2016).

\section{INDUCTORS}

Inductor is one of the basic electronic components having a wide variety of applications in various electronic circuits like oscillators, filters, transmitters etc (Richard and Travis, 2011). Raju and Murthy (2012), using the mechanical milling process have successfully synthesized a series of nano-composites of nickel-zinc ferrite paraformaldehyde. They reported that, with the increase in the volume of polymer, the permittivity, permeability, and dielectric and magnetic loss of all the composites decreases. The permittivity and permeability of all the composites have shown good frequency stability and low dielectric and magnetic losses within the measurement range. Such magnetic composites are candidates for capacitor-inductor integrating devices such as electromagnetic interference filters in RF communications.

Figure 10.1 shows the magnetic hysteresis curves of the composites under applied magnetic field at room temperature. The magnetization of PFD $+\mathrm{NiZn}$ ferrite nanocomposites exhibited a clear hysteretic behavior, and the area within the hysteresis loops was increased with increase in the ferrite content.

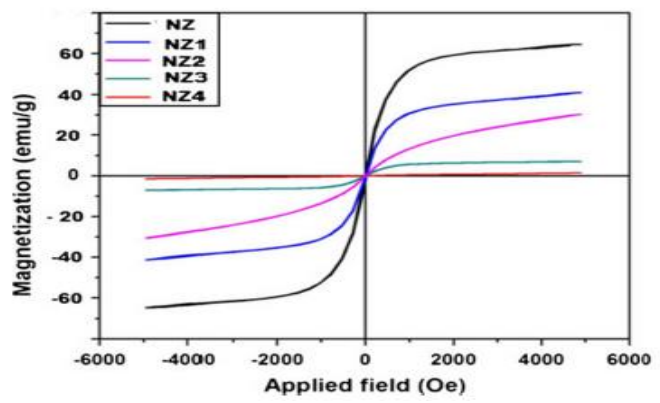

Fig. 10.1: VSM loops of $x$ PZF $+(1-x)$ NZF $(0 \leq x \geq 1)$ nanocomposites

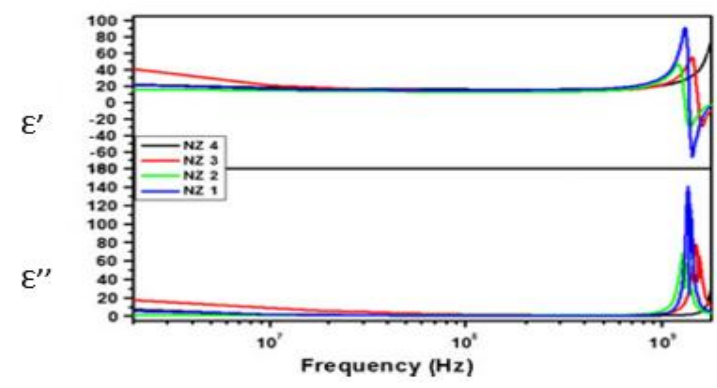

Fig. 10.2: Frequency dependence of real and imaginary parts of permittivity of $x \mathrm{PZF}+(1-\mathrm{x}) \mathrm{NZF}(0 \leq \mathrm{x} \geq 1)$ nanocomposites

Fig. 10.2 shows the variation of the real $\left(\mathcal{E}^{\prime}\right)$ and imaginary $\left(\mathcal{E}^{\prime \prime}\right)$ parts of permittivity with frequency at room temperature for all composites. It can be observed that the values of $\mathcal{E}^{\prime}$ and $\mathcal{E}^{\prime}$ ', increase with increasing ferrite content in composites, but are lower than those of the pure ferrite (NZ 1) (Raju and Murthy, 2012).

\section{CONCLUSION}

In recent years, nanostructured materials have received steadily growing attention as a result of their peculiar and fascinating properties and applications. In our contemporary 
era, sophisticated electronic devices rely on components that are made from what are called semiconducting materials. The good electrical, optical, magnetic, thermal and mechanical properties of $\mathrm{NiO}$ paved way to its applications in semiconductors, nickel cermet for the anode layer, batteries and solar cells, electrochromic devices, plastics and textiles, nanowires and nanofibers, antiferromagnetic layers, light weight structural components in aerospace, active optical filters, gas or temperature sensors, transparent heat mirrors, thermistors and varistors, glasses and glazes, optoelectronic devices, capacitors and supercapaciotrs, inductors, electromagnetic interference filters, antennas, tuned circuits, accelerators and radar absorbing materials.

\section{REFERENCES}

[1] Ahmad, F. A., Zulkifly, A., Suzan, J. O., and Abdalhadi, D. M. (2017). Improvement of Dielectric, Magnetic and Thermal Properties of OPEFB Fibre-Polycaprolactone Composite by Adding Ni-Zn Ferrite. Polymers 2017, vol.9, pp.1-15.

[2] Ahmad, F., Zulkifly, A., Mohamad, F. Z., Suzan, J., and AbuBakar, Y. (2015). Dielectric characterization of oil palm fiber reinforced polycaprolactone-nickel oxide composite at microwave frequency. Procedia Environmental Sciences, vol.30, pp.273 - 278.

[3] Al-Kuhaili, M. F., Ahmad, S. H. A., Durrani, S. M. A., Faiz, M. M., and Ul-Hamid, A. (2015). Application of nickel oxide thin films in $\mathrm{NiO} / \mathrm{Ag}$ multilayer energy-efficient coatings. Materials Science in Semiconductor Processing, vol.39, pp.84-89.

[4] AzoNano, (2013), Nickel Oxide (NiO) Nanoparticles: Properties, Applications retrieved from www.azonano.com/article.aspx?ArticleID $=3378$ on $7^{\text {th }}$ February, 2019.

[5] Banerjee, M., Mukherjee, S., and Maitra, S. (2012). Synthesis and characterization of nickel oxide doped barium strontium titanate ceramics. Cerâmica, vol.58, pp.99-104.

[6] Baptiste, P., Franck, T., François, C., Laurent, C., Fabrice, O., and Stéphane, J. (2016). Synthesis of Ni-poor NiO nanoparticles for pDSSC Applications. Solid State Sciences, vol.54, pp.37-42.

[7] Estrela, P. and Migliorato, P. (2007). Chemical and biological sensors using polycrystalline silicon TFTs," J. Mater. Chem., vol. 17(3), 219.

[8] Fasaki, I., M. Kandyla1, M. G. Tsoutsouva1, M. Kompitsas (2018). Optimized hydrogen sensing properties of nanocomposite $\mathrm{NiO}: \mathrm{Au}$ thin films grown by dual Pulsed Laser Deposition retrieved from www.laser-applications.eu on $12^{\text {th }}$ March, 2019.

[9] Gaurav, J., Jai, P., Achu, C., Jitendra, G., Srivastava, A. K., and Biradar, A. M. (2015). Effect of nickel oxide nanoparticles on dielectric and optical properties of nematic liquid crystal. AIP conference Proceedings vol.1675, pp.1-8.

[10] Hayati, A. (2018). Future MISFET gate dielectric: NiO/PVA Nanohybride composites. Journal of Interfaces, Thin films, and Low dimensional systems, vol.2, pp.65-72.

[11] Irudaya, S. S. L., Priya, D. M., Shally, V. and Gerardin, J. (2016). Effect of lithium doping concentration on the structural, morphological and optical properties of $\mathrm{NiO}$ nanoparticles. International Research Journal of Advanced Engineering and Science, vol. 1(2), pp. 55-58.

[12] Jason, S. T., Alexander, L. V., Nitin, P. P., Si-Young, P. and Paul, R. B., (2007). Characterization and Electrical Properties of Individual $\mathrm{Au}-\mathrm{NiO}-\mathrm{Au}$ Heterojunction Nanowires. IEEE Transactions on Nanotechnology, vol. 6(6), ppp.676-681.

[13] Jeon, N. J., Noh, J. H., Yang, W. S., Kim, Y. C., Ryu, S., Seo, J. and Seok, S. I. (2015). Compositional engineering of perovskite materials for high-performance solar cells, Nature, vol. 517(7535), 476-480.

[14] Jing, M. Wen, L., Shuyuan, Z., Zhe, M., Peishuai, S., Fuhua, Y. and Xiaodong, W. (2018). A Thin Film Flexible Supercapacitor Based on Oblique Angle Deposited Ni/NiO Nanowire Arrays. Nanomaterials, vol. 8(422), pp.1-10.

[15] Kasap, S. O. and Rowlands, J. A. (2000). X-ray photoconductors and stabilized a-Se for direct conversion digital flat-panel X-ray image-detectors, J. Mater. Sci. Mater. Electron, vol. 11(3), 179198

[16] Kingsley, O. U., Freddie, L. I. and Andrew, C. E. (2018) Fabrication of Affordable and Sustainable Solar Cells Using $\mathrm{NiO} / \mathrm{TiO} 2 \mathrm{P}-\mathrm{N}$ Heterojunction. International Journal of Photoenergy Vol. 2018, pp. 1-7.

[17] Kuo, Y. and Nominanda, H. (2006). Nonvolatile hydrogenatedamorphous-silicon thin-film-transistor memory devices," Appl. Phys. Lett., vol. 89(17), 1-4.

[18] Lalithambika, K. C., Thayumanavan, A. and Sriram, S. (2016). Electrode and substitutional effects on electronic transport properties of $\mathrm{NiO}$ nano devices. Der Pharma Chemica, vol. $8(2): 415-421$.

[19] Li, X., Lin, T., Shin, J. and Jang, J. (2016). Solution processed pchannel oxide thin film transistor employing metal doped nickel oxide," pp. 1221-1224.

[20] Liao, F., Chen, C. and Subramanian, V. (2005). Organic TFTs as gas sensors for electronic nose applications," Sensors Actuators, B Chem., vol. 107(2), 849-855.

[21] Liu, A., Liu, G., Zhu, H., Shin, B., Fortunato, E., Martins, R. and Shan, F. (2016). Hole mobility modulation of solution-processed nickel oxide thin-film transistor based on high-k dielectric, Appl. Phys. Lett., vol. 108(23)

[22] Michelle, P. B., Hugo, N., Nina, C. B., Georg, S. D., Paula, E. C. and Michael, E. G. L. (2016). Electrochromic Nickel Oxide Films for Smart Window Applications. Int. J. Electrochem. Sci., 11 (2016), pp.6636 - 6647 .

[23] Mohammad, K. and Leila, M. (2014). A Facile and Mild Method for Synthesis of Nickel Oxide Nanoparticles in the Presence of Various Surfactants. Research and Reviews: Journal of Material Sciences. Vol. 2(1), pp.37.

[24] Patel, K. J., Bhatt, G. G., Ray, J. R., Suryavanshi, P. and Panchal, C. J. (2016). Allinorganic solid-state electrochromic devices: review," J. Solid State Electrochem, pp. 1-11.

[25] Pei-Jiang, L., Zheng-Jun, Y., Vincent, M. H. N., Jin-Tang, Z., ZhiHong, Y., and Ling-Bing, K. (2018). Enhanced Microwave Absorption Properties of Double-Layer Absorbers Based on Spherical $\mathrm{NiO}$ and $\mathrm{Co}_{0.2} \mathrm{Ni}_{0.4} \mathrm{Zn}_{0.4} \mathrm{Fe}_{2} \mathrm{O}_{4}$ Ferrite Composites. Acta Metall. Sin. (Engl. Lett.), vol.31, pp.171-179.

[26] Pilban-Jahromi, S., Huang, N. M., Kamalianfar, A., Lim, H. N., Muhamad, M. R. and Yousefi, R. (2012). Facile synthesis of porous-structured nickel oxide thin film by pulsed laser deposition," J. Nanomater., vol. 2012.

[27] Raju, P., and Murthy, S. R. (2012). Preparation and characterization of $\mathrm{Ni}-\mathrm{Zn}$ ferrite + polymer nanocomposites using mechanical milling method. Appl Nanosci (2013). vol.3, pp.469475 .

[28] Ravi, K. G., Vijaya, K. K., and Venudhar, Y. C. (2012). Electrical Conductivity and Dielectric Properties of Copper Doped Nickel Ferrites Prepared By Double Sintering Method. International Journal of Modern Engineering Research (IJMER). Vol.2, Issue.2, pp.177-185

[29] Ravindra, N. K., Akhilesh, P., Suresh, K. G., and Vaishali, B. (2017). Magnetic and Enhanced Microwave Absorption Properties of Ni-Co-Zn Ferrite/Polyaniline Nano Composites. International Journal of Engineering Technology Science and Research (IJETSR), vol.5, pp.147

[30] Richard, C. J. and Travis N. B. (2011). Microelectronic Circuit Design $3^{\text {rd }}$ ed., The McGraw-Hill Companies, New York, America.

[31] Thomas, J., Macdonald, J. X., Sait, E., Yatin, J. M., William, M. S., Haolan, X. and Thomas, N. (2014). NiO Nanofibers as Candidate for a Nanophotocathode. Nanomaterials, vol. 2014(4), pp.256-266.

[32] Zhou, D. Dong, X., Xinhui, X., Xiuli, W., Changdong, G. and Jiangping, T. (2017). All-solid-state electrochromic devices based on $\mathrm{WO} 3 \| \mathrm{NiO}$ films: material developments and future applications. Science China Chemistry Vol. 60(3). 